\title{
Overgeneral autobiographical memory predicts higher prospective levels of depressive symptoms and intrusions in borderline patients
}

\author{
Kris Van den Broeck, Guido Pieters, Laurence Claes, Ann Berens \& Filip Raes
}

To cite this article: Kris Van den Broeck, Guido Pieters, Laurence Claes, Ann Berens \& Filip Raes (2015): Overgeneral autobiographical memory predicts higher prospective levels of depressive symptoms and intrusions in borderline patients, Memory, DOI: 10.1080/09658211.2015.1102938

To link to this article: http://dx.doi.org/10.1080/09658211.2015.1102938

Published online: 22 Oct 2015.

Submit your article to this journal ¿

Џ Article views: 18

Q View related articles $\sqsubset$

View Crossmark data ¿ 


\title{
Overgeneral autobiographical memory predicts higher prospective levels of depressive symptoms and intrusions in borderline patients
}

\author{
Kris Van den Broeck ${ }^{\mathrm{a}, \mathrm{b}}$, Guido Pieters ${ }^{\mathrm{a}, \mathrm{b}}$, Laurence Claes ${ }^{\mathrm{a}}$, Ann Berens ${ }^{\mathrm{c}}$ and Filip Raes $^{\mathrm{a}}$ \\ ${ }^{\mathrm{a}}$ Faculty of Psychology and Educational Sciences, University of Leuven, Leuven, Belgium; ${ }^{\mathrm{b}}$ University Psychiatric Centre KU Leuven, \\ Kortenberg, Belgium; 'Psychiatric Hospital Duffel, Duffel, Belgium
}

\begin{abstract}
Overgeneral memory (OGM), the tendency to retrieve categories of events from autobiographical memory instead of single events, is found to be a reliable predictor for future mood disturbances and post-traumatic symptom severity. Patients with borderline personality disorder (BPD) often report co-morbid episodes of major depressive disorder (MDD) and post-traumatic stress disorder (PTSD). Therefore, we investigated whether OGM would predict depression severity and (post-traumatic) stress symptoms in BPD patients. At admission $(N=54)$ and at six-month follow-up $(N \geq 31)$, BPD patients completed the Structured Clinical Interview for DSM-IV Disorders, the Assessment of DSM-IV Personality Disorders, the Autobiographical Memory Test, the Beck Depression Inventory-2nd edition (BDI-II), and the Impact of Event Scale. OGM at baseline predicted (a) higher levels of depressive symptoms at follow-up and (b) more intrusions related to a stressful event over and above baseline levels of borderline symptoms, depressive symptoms, and intrusions, respectively. No association was found between memory specificity and event-related avoidance at follow-up. Despite previous findings suggesting that OGM in BPD is less robust than in MDD and PTSD, our results suggest that memory specificity in BPD patients may have some relevance for the course of depressive and stress symptomatology in BPD.
\end{abstract}

\section{ARTICLE HISTORY}

Received 12 May 2015

Accepted 28 September 2015

\section{KEYWORDS}

Overgeneral memory;

borderline personality disorder; depression severity; post-traumatic symptom severity; intrusions
Patients suffering from major depressive disorder (MDD; American Psychiatric Association [APA], 2013) have robustly shown to have difficulties retrieving specific, detailed information from autobiographical memory (see Williams et al., 2007 for a review). Instead of recalling specific single events (e.g. "Last Friday, when I saw that Amy had forgotten her tennis shoes when she left for her

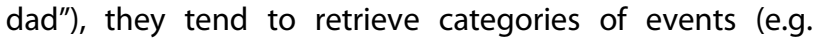
"Every Friday, when the children prepare themselves to stay the weekend at their father's place"). Because overgeneral memory (OGM) is found to be associated with less adaptive (avoidant) coping strategies (e.g. Hermans, Defranc, Raes, Williams, \& Eelen, 2005) and impaired social problem solving abilities (e.g. Goddard, Dritschel, \& Burton, 1996), OGM has been put forward as a potential vulnerability factor for depression (e.g. Gibbs \& Rude, 2004). A recent meta-analysis (Sumner, Griffith, \& Mineka, 2010) indeed found that there is a reliable (albeit small) relation between OGM and an unfavourable course of depression. The authors investigated 15 data sets, all containing data on the Autobiographical Memory Test (AMT) and depression severity at two time-points. Overall, their analyses revealed that higher levels of OGM at baseline predict higher levels of depressive symptoms at followup, over and above the level of depressive symptoms at baseline. Several recent studies corroborated the predictive value of OGM for future depression severity in an adult community sample (Van Daele, Griffith, Van den Bergh, \& Hermans, 2014), students (Anderson, Goddard, \& Powell, 2010; Boelen, Huntjens, \& van den Hout, 2013; Sumner, Mineka, \& McAdams, 2013), and younger adolescents (Hipwell, Sapotichne, Klostermann, Battista, \& Keenan, 2011; Sumner et al., 2011). These findings suggest that future mood disturbances could be mitigated by improving memory specificity in patients at risk. Indeed, when depressed participants were trained to become more specific, depression severity (Neshat-Doost et al., 2013) and rumination levels were found to decrease (Raes, Williams, \& Hermans, 2009).

OGM is also found in patients with post-traumatic stress disorder (PTSD; APA, 2013; see Moore \& Zoellner, 2007, for a review), and several studies suggest that OGM may have an important impact on post-traumatic symptom severity as well. For instance, reduced memory specificity was found to predict post-traumatic symptom severity at sixmonth follow-up in survivors of motor vehicle accidents (Harvey, Bryant, \& Dang, 1998) and assault victims (Kleim \& Ehlers, 2008), even when initial symptom severity was taken into account. Yet, Kangas, Henry, and Bryant (2005) found no evidence for OGM as a predictor of post-traumatic symptom severity in a sample of cancer patients. In women who were hospitalised following a complicated 
pregnancy, pregnancy-related memory specificity alone predicted post-traumatic stress and symptom severity at six weeks post-delivery (Hauer, Wessel, Engelhard, Peeters, \& Dalgleish, 2009). When baseline measures were kept constant, however, the impact of memory specificity was only marginally significant. These studies, though, do not exclude the possibility that OGM may be initiated following the traumatic event. Therefore, three studies have investigated whether pre-trauma levels of OGM were able to predict post-traumatic symptoms at follow-up. Memory specificity measured during the training stage of newly hired firefighters (pre-trauma) added to the prediction of post-traumatic symptom severity at four-year follow-up, even when controlled for pre-trauma PTSD or depression severity (Bryant, Sutherland, \& Guthrie, 2007). Second, in a non-clinical sample, Belcher and Kangas (2014) found that being more specific when retrieving past and future events may be protective for the development of intrusive images and thoughts during the week following exposure to a trauma film. A third study measured post-traumatic symptom severity with respect to an event that happened between baseline and follow-up (Boelen et al., 2013). In this study, higher levels of students' memory specificity, measured with the Sentence Completion for Past Events Test (Raes, Hermans, Williams, \& Eelen, 2007), predicted lower levels of post-traumatic symptom severity at one-year followup. Overall, these findings thus suggest that OGM may be a vulnerability factor for post-traumatic stress as well. Accordingly, and in line with what was found in depressed patients, Moradi and colleagues (2014) showed that memory specificity training in traumatised patients resulted in less intrusions and less avoidance symptoms in Iranian war veterans.

Different, albeit not mutually exclusive accounts have been proposed to explain OGM in depressed and traumatised patients. According to the functional avoidance (FA) hypothesis (Williams et al., 2007), an overgeneral retrieval style preserves the stability of one's self-concept, because important details and associated emotions of unpleasant past events are not reactivated. Although such a strategy may prevent the development of a (new) depressive episode in the short term, it has been suggested that it may lead to enduring post-traumatic symptoms or future mood disorders, perhaps because OGM undermines adequate social problem solving (Boelen et al., 2013; Evans, Williams, O'Loughlin, \& Howells, 1992; Sutherland \& Bryant, 2008), or maintains a reciprocal relation with ruminative processes (Boelen et al., 2013; Bryant et al., 2007; Kleim \& Ehlers, 2008). Cognitive models on PTSD suggest that OGM for traumatic memories may hinder the integration ("processing") of traumatic events with other autobiographical memories and one's self-concept (e.g. Dalgleish, 2004; Ehlers \& Clark, 2000; Foa \& Hearst-lkeda, 1996). Additionally, long-lasting intrusions are hypothesised to absorb resources that could otherwise be used for effortful memory search (McNally, Litz, Prassas, Shin, \&
Weathers, 1994; Wessel, Merckelbach, \& Dekkers, 2002). Finally, it is hypothesised that especially reduced specificity in imagining future events, which is assumed to use the same pathways than memory retrieval (Schacter, Addis, \& Buckner, 2007), contributes to future levels of post-traumatic stress (Belcher \& Kangas, 2014; Boelen et al., 2013).

Having knowledge of the predictors of psychopathological states helps to make the course of disorders predictable and transparent, and, as outlined above (Moradi et al., 2014; Neshat-Doost et al., 2013), predictors may provide clues for treatment. In this study, we investigated whether OGM also relates to future complaints in patients suffering from borderline personality disorder (BPD). In these patients, who often report co-morbid MDD and PTSD (Grant et al., 2008), an association between OGM and depression (severity) is only inconsistently found in cross-sectional studies (for a review, see Van den Broeck, Claes, Pieters, Hermans, \& Raes, 2015). To our knowledge, only one study (Kremers, Spinhoven, Van der Does, \& Van Dyck, 2006) investigated whether memory specificity at baseline would predict depression severity at 15 months in BPD patients. Measurements of memory specificity did not make a significant contribution above depression severity at baseline. The first aim of this study, therefore, was to clarify the relation between OGM and future mood symptoms in BPD patients. Based on the findings of Sumner et al. (2010), we hypothesised that OGM would predict future depressive symptoms at six-month follow-up. The second aim of this study was to investigate the potentially predictive value of OGM towards future stress symptoms in BPD patients. As far as we know, this has never been studied. Moreover, cross-sectional studies never revealed an association between OGM and a comorbid diagnosis of PTSD in BPD patients (Kremers, Spinhoven, \& Van der Does, 2004; Renneberg, Theobald, Nobs, \& Weisbrod, 2005). Yet, based on the findings in patients with PTSD, we hypothesised that OGM would predict the frequency of intrusive thoughts, and the attempts to avoid elements, related to the stressful experience-both central symptoms of PTSD (APA, 2013).

\section{Methods}

\section{Procedure and participants}

This study was part of a larger study investigating autobiographical memory in BPD patients. Following oral and written informed consent, participants were asked to complete a battery of tests and questionnaires. In the light of this study, relevant measures administered during initial testing were the SCID-II (Structured Clinical Interview for DSM-IV Disorders, Axis II), the SCID-I (Structured Clinical Interview for DSM-IV Disorders, Axis I) modules on MDD and PTSD, the AMT, the Assessment of DSM-IV Personality Disorders (ADP-IV), the Beck Depression Inventory-2nd edition (BDI-II), and the Impact of Event Scale (IES) (please see the Instruments section for more information). 
We used a computerised version of the ADP-IV, the BDI-II, and the IES, using the open-source software Limesurvey. Due to practical issues, data collection per participant often took more than one session, but in most cases a respondent's protocol was completed within a threeweek time span. Five months after initial testing, participants were contacted again by e-mail or by phone to make appointments for follow-up measurements. Reassessment took place in the hospital. All measures were reassessed, but for this study, we were especially interested in the BDI-II and the IES. The study was approved by the ethical committees of the University of Leuven and the psychiatric hospitals where the study was conducted.

Participants at $\mathrm{T} 1$ were 54 patients (8 males), all meeting DSM-IV BPD criteria (APA, 1994) according to the SCID-II interview (First, Gibbon, Spitzer, Williams, \& Benjamin, 1997; Dutch translation by Weertman, Arntz, \& Kerkhofs, 2000). All participants were between 18 and 51 years of age $(M=29.48, S D=8.37)$. They were recruited in two Belgian psychiatric hospitals: University Psychiatric Centre KU Leuven, Campus Kortenberg (77.78\%) and Psychiatric Hospital Duffel (22.22\%). Most patients were inpatients (79.63\%) staying at a general psychiatric ward (46.51\%), at a specialised unit treating BPD according to the principles of Dialectical Behavioural Therapy (34.88\%) or at a unit specialised in the treatment of anxiety disorders (18.60\%). Eleven patients followed day treatment and outpatient emotional skills trainings, organised by the abovementioned hospitals.

At six-month follow-up, complete data were available for 31 of the original 54 participants. Four patients could not be reached for follow-up, 10 participants refused to take part in the study at $\mathrm{T} 2$, and nine participants had incomplete protocols. Table 1 displays the sample characteristics for the total sample at $\mathrm{T} 1$ and the reduced sample of patients that were involved at T2 $(n=35)$. As can be derived from Table 2, patients with complete and incomplete follow-up data did not differ significantly at baseline with respect to the variables of interest (AMT, ADP-IV borderline trait score, BDI-II, IES). ADP-IV borderline trait scores at $\mathrm{T} 2$ were significantly lower than those at $\mathrm{T} 1, t(32)=2.92$, $p<.01$. Likewise, $\mathrm{BDI}-\mathrm{II}$ scores at $\mathrm{T} 2$ were significantly lower than those at $\mathrm{T} 1, t(32)=2.80, p<.01$, ranging from the "severely depressed" (T1) scoring range to "moderately depressed" (T2). AMT measures and IES scales at T1 did not differ from those at T2 (all $p s>$.277).

\section{Instruments}

Structured Clinical Interview for DSM-IV Disorders, Axis II (First, Gibbon et al., 1997; Dutch translation by Weertman et al., 2000). This semi-structured interview systematically assesses DSM-IV Axis II disorders (APA, 1994). All SCID-II interviews were conducted by the first author, who is trained to use the SCID-II. The SCID-II items were scored on a 3-point scale ranging from not applicable, applicable but not sufficiently present, to present. Scores reflect the
Table 1. Sample characteristics at T1 for the total sample $(n=54)$ and for the subsample $(n=35)$ with complete or incomplete data at T2.

\begin{tabular}{lcc}
\hline & $\begin{array}{c}\text { Total sample } \\
(n=54 ; 8 \text { males })\end{array}$ & $\begin{array}{c}\text { Subsample } \\
(n=35 ; 5 \text { males })\end{array}$ \\
\hline Age $(M$, SD) & $29.48(8.37)$ & $30.60(8.45)$ \\
Education level (\%) & & \\
$\quad$ Primary school & 9.3 & 8.6 \\
High school & 53.7 & 48.6 \\
College & 25.9 & 28.6 \\
$\quad$ University & 11.1 & 14.3 \\
Civil state (\%) & & \\
$\quad$ Single & 63.0 & 71.4 \\
$\quad$ Living together & 26.0 & 17.1 \\
$\quad$ Married & 3.7 & 2.9 \\
$\quad$ Divorced & 7.4 & 8.6 \\
Occupation (\%) & & \\
$\quad$ Student & 9.3 & 5.7 \\
Unemployed & 38.9 & 37.1 \\
$\quad$ Working/on sick leave & 48.1 & 54.3 \\
$\quad$ Other & 3.7 & 2.9 \\
N Kortenberg/N Duffel & $42 / 12$ & $26 / 9$ \\
N Inpatient/N outpatient & $43 / 11$ & $24 / 11$ \\
Inpatient (\%) at & & \\
$\quad$ General psychiatric ward & 46.5 & 50.0 \\
$\quad$ Specialised DBT unit & 34.9 & 37.5 \\
Specialised anxiety unit & 18.6 & 12.5 \\
\hline
\end{tabular}

presence or absence of 12 personality disorders (all DSMIV personality disorders plus depressive and passiveaggressive personality disorder). Interrater reliability of the SCID-II ranges from .90 to .98 for dimensional judgements and internal consistency ranges from .71 to .94 (Maffei et al., 1997).

Structured Clinical Interview for DSM-IV Disorders, Axis I (First, Spitzer, Gibbon, \& Williams, 1997; Dutch translation by van Groenestijn, Akkerhuis, Kupka, Schneider, \& Nolen, 1999). This semi-structured interview assesses DSM-IV Axis I disorders (APA, 1994). We only administered the MDD and PTSD modules. Again, interviews were performed by the first author. For the module on MDD, satisfactory test-retest reliability $(\kappa=.61)$ and interrater reliability $(\kappa=.80)$ are reported (Zanarini et al., 2000). Similarly, for the module on PTSD, satisfactory test-retest

Table 2. Depressive state, depression severity, BPD symptom severity, severity of intrusions, and avoidance behaviour, and measures of memory specificity at T1 $(n=54)$ and T2 $(n=34$, except for BDI and ADP-IV: $n=33)$.

\begin{tabular}{lll}
\hline \multicolumn{1}{c}{ T1 } & \multicolumn{1}{c}{ T2 } \\
\hline SCID-I & \multicolumn{1}{c}{ ( } & \multicolumn{1}{c}{5} \\
$\quad$ Current depressed & 18 & 25 \\
$\quad$ Remitted depressed & 26 & 4 \\
$\quad$ Never depressed & 10 & $25.30(16.28)$ \\
BDI & $30.93(13.27)$ & $4.42(1.36)$ \\
ADP-IV BPD trait score & $5.04(1.10)$ & \\
IES & & $39.85(19.42)$ \\
$\quad$ Total score & $41.75(17.42)$ & $19.56(10.70)$ \\
Intrusions & $21.36(10.20)$ & $20.29(10.48)$ \\
$\quad$ Avoidance & $20.40(9.37)$ & \\
AMT & & $14.70(2.33)$ \\
$\quad$ Number of specific memories & $14.59(2.39)$ & $0.74(1.38)$ \\
$\quad$ Number of categoric memories & $0.96(1.16)$ & \\
\hline
\end{tabular}

Note: SCID-I = depression module of the Structured Clinical Interview for DSM-IV Disorders, Axis I; BDI=Beck Depression Inventory; ADP-IV = Assessment of DSM-IV Personality Disorders; IES = Impact of Event Scale; AMT $=$ Autobiographical Memory Test. 
reliability $(\kappa=.78)$ and interrater reliability $(\kappa=.88)$ are reported (Zanarini et al., 2000).

Autobiographical Memory Test (Williams \& Broadbent, 1986; Dutch version). In this test, respondents are presented with 18 cues (happy, sad, safe, angry, interested, clumsy, successful, emotionally hurt, surprised, lonely, relaxed, guilty, proud, afraid, pleasant, cowardly, carefree, and lazy) that are read aloud by the experimenter. Participants are invited to retrieve specific memories that the cues remind them of. The definition of a specific autobiographical memory is explained by using an example. Three example cues are presented before the actual task to check whether the participants understood the assignment. The experimenter immediately codes the answers as "specific", "general categoric" (if the response refers to a category of events), "general extended" (if the answer refers to an event that took longer than one day), "no memory" (e.g. a semantic association in response of the cue), or "same event" (whenever the retrieved memory is identical to a memory retrieved in response to a previous cue). If respondents first retrieve a general memory or a memory that had been retrieved earlier in response to another cue, they are prompted to search for specific memories again. If no memory is found in 60 seconds, the next cue is presented and the answer is coded as "omission". We were especially interested in the number of general categoric memories retrieved. We further computed the number of specific memories retrieved, and, to correct for the number of omissions, the proportions of specific and general categoric memories. ${ }^{1}$ AMT administration was audiotaped. A random sample of $10 \%$ of the answers to AMT cues were re-coded by a second rater. Interrater reliability was .89 , over both AMT admissions.

Assessment of DSM-IV Personality Disorders (Schotte, De Doncker, \& Courjaret, 2007). Each of the 94 ADP-IV statements represents a personality disorder criterion, and respondents are asked to indicate to what extent they agree with each of the statements, ranging from 1 (totally disagree) to 7 (totally agree). Higher scores indicate higher levels of symptom severity. Good validity is reported (Schotte et al., 2004). In the light of this study, we were exclusively interested in the total BPD trait score. This score, the average of the 10 BPD-relevant items of the ADP-IV, represents BPD symptom severity.

Beck Depression Inventory-II (Beck, Steer, \& Brown, 1996; authorised Dutch translation (BDI-II-NL) by Van der Does, 2002). This self-report questionnaire measures depression severity. It consists of 21 items, each representing a specific depressive symptom (e.g. pessimism, guilt, suicidal ideations). An item consists of four statements indicating different levels of severity. Participants are asked to mark the statements that best describe how they felt during the last two weeks, the current day included. Item scores differ from 0 to 3 ; total score ranges from 0 to 63 with higher scores indicating higher levels of depressive symptoms. The internal consistency of the total BDI-II in our sample (at T1) was high, Cronbach's alpha equal to .91.
Impact of Event Scale (Horowitz, Wilner, \& Alvarez, 1979; authorised Dutch translation (Schokverwerkingslijst) by Brom and Kleber (1985). The Dutch version of this questionnaire counts 15 items, and aims to inventory to what extent one suffered from trauma-related intrusive thoughts, feelings, and images (7 items), and from avoidance of traumarelated stimuli, thoughts, and feelings (8 items) during the preceding seven days. Prior to these questions, respondents are invited to briefly describe a traumatic event that they will keep in mind while answering the items. Each item is scored on a 4-point scale, from not at all (0), over seldom (1) and sometimes (3) to often (5), expressing how often what is described in the item caused trouble during the week prior to testing. Total score ranges from 0 to 75; the Intrusions and Avoidance subscales range from 0 to 35 , and from 0 to 40, respectively. The internal consistency of the IES scales in our sample (at T1) was high, Cronbach's alpha $=.88$, Cronbach's alpha $=.90$, and Cronbach's alpha $=.73$, for IES total score, IES Intrusions, and IES Avoidance, respectively.

\section{Results \\ Descriptives}

At six-month follow-up, complete data were available for 31 of the original 54 participants. Nine participants had incomplete protocols. ${ }^{2}$ Regression analyses predicting BDI-II and IES scores at T2 could be conducted for 33 and 34 participants, respectively.

The IES was completed on traumatic experiences related to personal assaults ( $n=10$ at T1; $n=12$ at T2); interpersonal problems $(n=7 ; n=5)$; the death or parting of a family member $(n=6 ; n=7)$; personal illness $(n=4$; $n=2)$; illness of a family member $(n=3 ; n=1)$ or other experiences that could not be classified in one of the categories above $(n=4 ; n=6)$. One trauma description was missing at T2. Although the life event reported at T1 could differ from that at T2, most respondents thought about a similar kind of event at both times, $x^{2}=77.20$, $p<.001$.

\section{Prediction of depression severity at six months follow-up}

Table 3 presents the correlations between the baseline variables (AMT, ${ }^{3}$ ADP-IV, BDI-II) and BDI-II scores at follow-up. Given the high correlation between the number of specific (S) and categoric memories (GC), we decided to conduct separate regression analyses, both with BDI-II scores at T2 as the dependent variable. To control for borderline symptom severity, depression severity and depressive state at T1, ADP-IV BPD trait score, BDI-II score and depressive state (current/remitted depressed vs. never depressed) at T1 were entered in Block 1. S and GC were entered in Block 2, respectively. Results are presented in Table 4 . Block 1 accounted for $49.8 \%$ of the variance of 
Table 3. Correlations between BPD symptom severity, depression severity, IES scales, and number of specific and general categoric memories at T1, and depression severity and IES scales at T2.

\begin{tabular}{|c|c|c|c|c|c|c|c|c|c|c|}
\hline & 2 & 3 & 4 & 5 & 6 & 7 & 8 & 9 & 10 & 11 \\
\hline 1. ADP-IV (T1) & $.44^{* *}$ & .23 & .24 & .17 & .01 & -.20 & $.44^{* *}$ & .20 & .20 & .15 \\
\hline 2. $\mathrm{BDI}(\mathrm{T} 1)$ & & $.53^{* *}$ & $.50 * *$ & $.46^{* *}$ & $-.36^{*}$ & .21 & $.69^{* *}$ & $.38^{*}$ & $.44^{* *}$ & .25 \\
\hline 3. IES (T1) & & - & $.90^{* *}$ & $.90^{* *}$ & -.12 & .03 & .31 & $.43^{*}$ & $.37^{*}$ & $.42^{*}$ \\
\hline 4. Intrus. (T1) & & & - & $.62^{* *}$ & -.13 & .12 & $.35^{*}$ & $.37^{*}$ & $.39^{*}$ & .29 \\
\hline 5. Avoid. (T1) & & & & - & -.09 & -.07 & .20 & $.41^{*}$ & .29 & $.46^{* *}$ \\
\hline 6.5 & & & & & - & $-.74^{* *}$ & $-.50^{* *}$ & $-.40^{*}$ & $-.43^{* *}$ & -.29 \\
\hline 7. GC & & & & & & - & .17 & $.36^{*}$ & $.47^{* *}$ & .20 \\
\hline 8. BDI (T2) & & & & & & & - & .31 & $.41^{*}$ & .17 \\
\hline 9. IES (T2) & & & & & & & & - & $.92^{* *}$ & $.92^{* *}$ \\
\hline 10. Intrus. (T2) & & & & & & & & & - & $.69 * *$ \\
\hline 11. Avoid. (T2) & & & & & & & & & & - \\
\hline
\end{tabular}

Note: ADP-IV = Assessment of DSM-IV Personality Disorders, BPD trait score; BDI = Beck Depression Inventory; IES = total score of the Impact of Event Scale; Intrus = Intrusions scale of the IES; Avoid = Avoidance scale of the IES; $S=$ number of specific memories retrieved during Autobiographical Memory Test administration; $\mathrm{GC}=$ number of general categoric memories retrieved.

${ }^{*} p<.05$.

${ }^{* *} p<.01$.

the BDI-II scores at follow-up, with only BDI-II scores at T1 reaching significance. Unlike $G C$, adding $S^{4}$ in Block 2 to the equation significantly increased $R^{2}$ with $11.2 \%, F_{\text {change- }}$ $=8.03, p<.01$. This means that higher levels of memory specificity at $\mathrm{T} 1$ predict lower levels of depressive symptoms at $\mathrm{T} 2$, when controlled for borderline symptoms, depressive symptoms and depressive state at $\mathrm{T} 1$.

\section{Prediction of IES at six months follow-up}

Table 3 also presents the correlations between ADP-IV BPD trait score, IES scales, $S$, and GC at baseline, and IES scales at follow-up. $S$ and $G C$ at T1 were significantly associated with IES total score and IES Intrusions at T2, but not with IES Avoidance. We therefore conducted regression analyses

Table 4. Summary of the hierarchical regression analyses results for the variables predicting depression severity (BDI) at six months $(n=33)$.

\begin{tabular}{|c|c|c|c|c|c|c|}
\hline & B & SE $B$ & $\beta$ & $p$-Value & $R^{2}$ & $p$-Value \\
\hline \multicolumn{7}{|l|}{ DV: BDI-6 months } \\
\hline \multicolumn{7}{|l|}{ Step 1} \\
\hline Constant & -9.86 & 10.66 & & & & \\
\hline ADP-IV-T1 & 2.34 & 2.08 & .17 & .271 & & \\
\hline $\mathrm{BDI}-\mathrm{T} 1$ & .76 & .19 & .61 & $<.001$ & & \\
\hline $\begin{array}{l}\text { Depressed state (ever } \\
\text { vs. never depressed) }\end{array}$ & .03 & 5.66 & .00 & .996 & .50 & $<.001$ \\
\hline \multicolumn{7}{|l|}{ Step 2} \\
\hline Constant & 26.16 & 15.90 & & & & \\
\hline ADP-IV-T1 & 3.94 & 1.95 & .28 & .053 & & \\
\hline BDI-T1 & .54 & .19 & .43 & .008 & & \\
\hline $\begin{array}{l}\text { Depressed state (ever } \\
\text { vs. never depressed) }\end{array}$ & -.75 & 5.09 & .02 & .884 & & \\
\hline $\begin{array}{l}\text { Number of specific } \\
\text { memories }\end{array}$ & -2.48 & .87 & -.38 & .008 & .61 & $<.001$ \\
\hline \multicolumn{7}{|l|}{ Step 2} \\
\hline Constant & -11.99 & 11.34 & & & & \\
\hline ADP-IV-T1 & 2.71 & 2.19 & .20 & .227 & & \\
\hline BDI-T1 & .72 & .20 & .58 & .001 & & \\
\hline $\begin{array}{l}\text { Depressed state (ever } \\
\text { vs. never depressed) }\end{array}$ & .48 & 5.77 & .01 & .934 & & \\
\hline $\begin{array}{l}\text { Number of categoric } \\
\text { memories }\end{array}$ & 1.05 & 1.75 & .09 & .552 & .50 & $<.001$ \\
\hline
\end{tabular}

Note: When DV (Dependent Variable) $=\mathrm{BDI}$ at six months: $\Delta R^{2}=.11$ for Step $2(p=.008)$ when adding number of specific memories at $\mathrm{T} 1$ as a predictor. $\Delta R^{2}=.00$ for Step $2(p=.552)$ when adding number of categoric memories at $\mathrm{T} 1$ as a predictor. with IES total score (Table 5) and IES Intrusions (Table 6) at $\mathrm{T} 2$ as dependent variables, and AMT variables as independent variables, controlling for IES total score and IES Intrusions at T1, respectively, besides PTSD status. We did not include ADP-IV BPD severity scores in Block 1, because ADP-IV scores at T1 were unrelated to IES total score nor IES Intrusions at T2, respectively. Both S and GC added significantly to the prediction of both IES total score $^{5}$ and IES Intrusions at T2. This means that higher levels of memory specificity at $\mathrm{T} 1$ predict lower frequencies of intrusions at T2, when controlled for IES total scores and IES Intrusions at $\mathrm{T} 1$, respectively.

\section{Discussion}

This study investigated the predictive value of OGM for depression severity and post-traumatic symptoms at sixmonth follow-up in a sample of BPD patients. Depression severity at follow-up was predicted by the number of specific memories retrieved at baseline, over and above baseline borderline and depression severity levels. More specific memories at baseline thus correspond with lower levels of depression six months later. This finding was replicated for the proportions of specific memories. Analyses using the number or proportion of categoric memories as predictors, however, did not corroborate these findings. Furthermore, in line with our expectations, memory specificity (both number and proportions of specific and categoric memories) predicted the frequency of traumatic (or stress related) intrusions, even when we controlled for the presence of intrusions at baseline. Contrary to our expectations, we found no association between avoidance levels at follow-up and memory specificity at baseline. Still, these findings suggest that, although cross-sectional associations between OGM and MDD and PTSD in BPD patients are inconsistently found (Van den Broeck et al., 2015), OGM in BPD patients may still be of relevance, in that it has some predictive value for the course of posttraumatic/stress related and, to a lesser extent, depressive symptomatology that often is reported by BPD patients. 
Table 5. Summary of the hierarchical regression analyses results for the variables predicting IES total score at six months ( $n=34)$.

\begin{tabular}{|c|c|c|c|c|c|c|}
\hline & $B$ & SE $B$ & $\beta$ & $p$-Value & $R^{2}$ & $p$-Value \\
\hline \multicolumn{7}{|l|}{ DV: IES-6 months } \\
\hline \multicolumn{7}{|l|}{ Step 1} \\
\hline Constant & 22.89 & 7.75 & & & & \\
\hline IES-T1 & .35 & .20 & .34 & .087 & & \\
\hline PTSD at T1 (current vs. no PTSD) & 6.83 & 7.66 & .17 & .380 & .21 & .028 \\
\hline \multicolumn{7}{|l|}{ Step 2} \\
\hline Constant & 65.74 & 19.19 & & & & \\
\hline IES-T1 & .30 & .19 & .28 & .124 & & \\
\hline PTSD at T1 (current vs. no PTSD) & 7.64 & 7.14 & .19 & .293 & & \\
\hline Number of specific memories & -2.80 & 1.16 & -.36 & .022 & .34 & .022 \\
\hline \multicolumn{7}{|l|}{ Step 2} \\
\hline Constant & 18.40 & 7.58 & & & & \\
\hline IES-T1 & .34 & .19 & .33 & .080 & & \\
\hline PTSD at T1 (current vs. no PTSD) & 6.85 & 7.22 & .17 & .351 & & \\
\hline Number of categoric memories & 5.13 & 2.31 & .33 & .034 & .32 & .034 \\
\hline
\end{tabular}

Note: When DV (Dependent Variable) = IES total score at six months: $\Delta R^{2}=.13$ for Step $2(p=.025)$ when adding number of specific memories at T1 as a predictor. $\Delta R^{2}=.11$ for Step $2(p=.034)$ when adding number of categoric memories at T1 as a predictor.

Put otherwise, our findings in this sample of BPD patients extend previous findings in non-BPD samples, thereby corroborating the predictive role of OGM for future symptoms that has repeatedly been found.

Although this study is in line with previous findings on OGM predicting the course of depression (Sumner et al., 2010), it contradicts the only study conducted in BPD patients focusing on the predictive value of OGM for depression severity: Kremers et al. (2006) found that memory specificity was not a significant predictor for depression severity at 15 months follow-up in a sample of BPD patients. Perhaps the longer time between T1 and T2 (15 months) in Kremers et al.'s study could explain the results. Indeed, Sumner et al. (2010) in their meta-analysis found that the impact of memory specificity on future mood declines when time-points are further apart. Alternatively, it should be noted that Kremers et al. used an adapted version of the standard AMT (Williams \& Broadbent, 1986), in which participants were explicitly instructed to retrieve "moments at which they exhibited the trait" that was used as a cue. We were less stringent during the AMT administration, and used the standard AMT-instructions, asking participants to retrieve specific memories "that the cue reminded them of". Nevertheless, given that only two studies are available today with inconsistent findings, replication is necessary to further explore the role of OGM (in co-morbid disorders and associated symptoms) in BPD patients.

Our study also extends previous findings on OGM as a predictor of post-traumatic symptom severity, that is, the frequency of intrusions and IES total score, which has never been studied in a sample of BPD patients. It should be noted, however, that many of the events that patients kept in mind when filling out the IES could not be considered as criterion $A$ traumatic events as defined in the DSM (APA, 1994). Therefore, the intrusions mentioned above should be interpreted as referring to stressful events, rather than to traumatic ones.

Although both intrusions and avoidance are considered core features of PTSD and MDD, we found no association between OGM at T1 and (cognitive, behavioural, emotional) avoidance at T2. This may seem odd, especially when taking the CaR-FA-X model (Williams et al., 2007) into account. This often cited model suggests that OGM may

Table 6. Summary of the hierarchical regression analyses results for the variables predicting IES Intrusions at six months ( $n=34$ ).

\begin{tabular}{|c|c|c|c|c|c|c|}
\hline & $B$ & SE $B$ & $\beta$ & $p$-Value & $R^{2}$ & $p$-Value \\
\hline \multicolumn{7}{|l|}{ DV: IES Intrusions-6 months } \\
\hline \multicolumn{7}{|l|}{ Step 1} \\
\hline Constant & 11.40 & 4.05 & & & & \\
\hline IES Intrusions-T1 & .39 & .21 & .38 & .071 & & \\
\hline PTSD at T1 (current vs. no PTSD) & .07 & 4.53 & .00 & .988 & .15 & .083 \\
\hline \multicolumn{7}{|l|}{ Step 2} \\
\hline Constant & 37.34 & 10.69 & & & & \\
\hline IES Intrusions-T1 & .32 & .19 & .32 & .107 & & \\
\hline PTSD at T1 (current vs. no PTSD) & .72 & 4.17 & .03 & .865 & & \\
\hline Number of specific memories & -1.70 & .66 & -.40 & .015 & .30 & .015 \\
\hline \multicolumn{7}{|l|}{ Step 2} \\
\hline Constant & 9.24 & 3.77 & & & & \\
\hline IES Intrusions-T1 & .32 & .19 & .31 & .108 & & \\
\hline PTSD at T1 (current vs. no PTSD) & .84 & 4.13 & .04 & .840 & & \\
\hline Number of categoric memories & 3.50 & 1.29 & .41 & .011 & .32 & .011 \\
\hline
\end{tabular}

Note: When DV (Dependent Variable) = IES Intrusions at six months: $\Delta R^{2}=.16$ for Step $2(p=.013)$ when adding number of specific memories at T1 as a predictor. $\Delta R^{2}=.17$ for Step $2(p=.010)$ when adding number of categoric memories at $\mathrm{T} 1$ as a predictor. 
result from a cognitive avoidance strategy which disturbs autobiographical memory search processes. Yet, it should be noted that Williams et al. (2007) also refer to "Capture and rumination" (CaR; getting stuck in superficial ruminative thoughts) and reduced executive functions $(X)$ as potential mechanisms underlying OGM, besides FA. In addition, the applicability of the CaR-FA-X model on BPD patients has been questioned (e.g. Van den Broeck, 2015). It has been suggested that BPD patients use behavioural coping strategies rather than cognitive avoidance strategies (e.g. non-suicidal self-injury instead of OGM; Van den Broeck et al., in press). Alternatively, and with respect to our sample of BPD patients, the non-significant associations between measures of memory specificity at $\mathrm{T} 1$ and IES Avoidance at T2 may be due to a lack of power. Finally, reviewing previous findings, Wessel et al. (2002) conclude that inconsistent findings may reflect the unreliability of the IES. Indeed, in cross-sectional studies, sometimes IES Avoidance, but not IES Intrusion was associated with memory specificity (e.g. Brewin, Watson, McCarthy, Hyman, \& Dayson, 1998; Kuyken \& Brewin, 1995), whereas others found AMT-performance to be related with IES Intrusions, but not with IES Avoidance (e.g. Brewin, Reynolds, \& Tata, 1999). To our knowledge, except for Hauer et al. (2009), studies focusing on the predictive value of OGM for post-traumatic symptom severity have never used the IES to measure post-traumatic stress. In addition, none of these prospective studies has reported on facets of traumatic stress. Based on these findings, we tentatively hypothesise that some BPD patients-particularly those who report few specific memories on the AMT -may profit from memory specificity training (MeST; Raes et al., 2009) as demonstrated in depressed (NeshatDoost et al., 2013) and traumatised patients (Moradi et al., 2014).

Of course, our study is not without limitations. We did not include measures on executive functioning, rumination, social problem solving, and future imagining, which prevents us from disentangling the mechanisms beyond OGM. We neither included a clinical non-BPD control group in our design. Furthermore, it should be noted that we tested our hypotheses in a rather small sample of BPD patients, which is important, given the heterogeneity of the BPD diagnosis. Nevertheless, our results suggest that, although cross-sectional associations between OGM and MDD and PTSD in BPD patients are inconsistently found, OGM in BPD patients too may be relevant in order to mitigate the course of depression and stress related symptoms.

\section{Notes}

1. To preserve maximum readability, we do not report the results for the proportional indices of specific (\%S) and categoric (\%GC) memories, unless they are different from the results using the plain number of specific (S) and categoric (GC) memories.

2. For five of them, both the BDI-II and the IES at T2 were missing. One participant completed the BDI-II at T2, but not the IES at T1.
Another one completed both the IES and the BDI-II at T2, but had missing data on the SCID-I at T2. BDI-II scores at T2 were missing for two other participants (of which one also had missing data on the AMT at T2).

3. Besides the standard AMT, we also administered a personalised AMT for each respondent, consisting of the 10 most self-discrepant self-guides the respondent formulated. According to Conway, Singer, and Tagini (2004), cues that tap into domains that are highly self-discrepant towards one's actual self-concept evoke more overgeneral memories. However, as reported elsewhere, pAMT administration in BPD patients resulted in less categoric memories and more omissions than standard AMT administration (Van den Broeck, 2015). Also, in this study, no association was found between memory specificity measured with the pAMT at $\mathrm{T} 1$ and depression severity and the IES scales at T2.

4. Adding the proportion of specific memories in Block 2 to the equation also resulted in a significant $\Delta R^{2}, R_{\text {change }}^{2}=.07$ with $F_{\text {change- }}$ $=4.70, p=.04$, with $\beta=-.29, t=-2.17, p=.04$, when predicting BDI-Il scores at $\mathrm{T} 2$.

5. Adding the proportion of specific memories in Block 2 to the equation resulted in a marginally significant $\Delta R^{2}, R_{\text {change }}^{2}=.096$ with $F_{\text {change }}=3.110, p=.052$, with $\beta=-.31, t=-2.03, p=.052$, when predicting IES total score at T2.

\section{Acknowledgements}

We would like to thank all the patients of UPC KU Leuven, Campus Kortenberg, and Psychiatric Hospital Duffel who participated in the study, as well as all staff members of the departments hosting these patients. Special thanks go to Vanessa Aerts, Tom Baeten, Marion Franssen, Dr Philip Haake, MD (passed away), Jos Lemmens, Marianne Nieulandt, and Stef Stuelens, for referring patients for inclusion, and to David Stuers for his contribution in calculating interrater reliability of the AMT output.

\section{Disclosure}

No potential conflict of interest was reported by the authors. Although some of the authors are employed by UPC KU Leuven, Campus Kortenberg, or the Psychiatric Hospital, Duffel, we declare that these organisations did not provide any input concerning the study design; the collection, analysis, and interpretation of the data; the writing of the report; and the decision to submit the paper for publication.

\section{Funding}

Personnel costs of this research have been funded by UPC KU Leuven Campus Kortenberg, Leuvensesteenweg 517, B-3070 Kortenberg, Belgium, and by the Research Foundation Flanders (Fonds Wetenschappelijk Onderzoek Vlaanderen) [grant number 1900114N].

\section{References}

American Psychiatric Association. (1994). Diagnostic and statistical manual of mental disorders (4th ed.). Washington, DC: Author.

American Psychiatric Association. (Ed.). (2013). Diagnostic and statistical manual of mental disorders (5th ed.). Washington, DC: Author.

Anderson, R. J., Goddard, L., \& Powell, J. (2010). Reduced specificity of autobiographical memory as a moderator of the relationship between daily hassles and depression. Cognition \& Emotion, 24, 702-709. doi:10.1080/02699930802598029

Beck, A. T., Steer, R. A., \& Brown, G. K. (1996). Manual for the Beck depression inventory-II. San Antonio, TX: Psychological.

Belcher, J., \& Kangas, M. (2014). Autobiographical memory and imagining future personal events: Event specificity and symptoms of 
depression and stress following exposure to an analogue trauma. Stress \& Health. doi:10.1002/smi.2567

Boelen, P. A., Huntjens, R. J. C., \& van den Hout, M. A. (2013). Concurrent and prospective associations of habitual overgeneral memory and prospection with symptoms of depression, general anxiety, obsessive compulsiveness, and post-traumatic stress. Memory. Advance online publication. doi:10.1080/09658211.2013.824985

Brewin, C. R., Reynolds, M., \& Tata, P. (1999). Autobiographical memory processes and the course of depression. Journal of Abnormal Psychology, 108, 511-517. doi:10.1037/0021-843X.108.3.511

Brewin, C. R., Watson, M., McCarthy, S., Hyman, P., \& Dayson, D. (1998). Intrusive memories and depression in cancer patients. Behaviour Research and Therapy, 36, 1131-1142. doi:10.1016/S0005-7967(98) 00084-9

Brom, D., \& Kleber, R. J. (1985). De Schok Verwerkings Lijst [The Dutch version of the Impact of Event Scale]. Nederlands Tijdschrift voor de Psychologie, 40, 164-168.

Bryant, R. A., Sutherland, K., \& Guthrie, R. M. (2007). Impaired specific autobiographical memory as a risk factor for posttraumatic stress after trauma. Journal of Abnormal Psychology, 116, 837-841. doi:10.1037/0021-843X.116.4.837

Conway, M. A., Singer, J. A., \& Tagini, A. (2004). The self and autobiographical memory: Correspondence and coherence. Social Cognition, 22, 491-529. doi:10.1521/soco.22.5.491.50768

Dalgleish, T. (2004). Cognitive approaches to posttraumatic stress disorder: The evolution of multirepresentational theorizing. Psychological Bulletin, 130, 228-260. doi:10.1037/0033-2909.130.2.228

Ehlers, A., \& Clarck, D. M. (2000). A cognitive model of posttraumatic stress disorder. Behaviour Research and Therapy, 38, 319-345. doi: 10.1016/S0005-7967(99)00123-0

Evans, J., Williams, J. M. G., O'Loughlin, S., \& Howells, K. (1992). Autobiographical memory and problem-solving strategies of parasuicide patients. Psychological Medicine, 22, 399-405. doi:10.1017/ S0033291700030348

First, M. B., Gibbon, M., Spitzer, R. L., Williams, J. B. W., \& Benjamin, L. S. (1997). Structured clinical interview for DSM-IV Axis II disorders. Washington, DC: American Psychiatric Press.

First, M. B., Spitzer, R. L., Gibbon, M., \& Williams, J. B. W. (1997). Structured clinical interview for DSM-IV Axis I disorders. Washington, DC: American Psychiatric Press.

Foa, E. B., \& Hearst-Ikeda, D. (1996). Emotional dissociation in response to trauma: An information processing approach. In L. K. Michelson \& W. J. Ray (Eds.), Handbook of dissociation: Theoretical, empirical, and research perspectives (pp. 207-224). New York, NY: Plenum Press.

Gibbs, B. R., \& Rude, S. S. (2004). Overgeneral autobiographical memory as depression vulnerability. Cognitive Therapy and Research, 28, 511-526. doi:10.1023/B:COTR.0000045561.72997.7c

Goddard, L., Dritschel, B., \& Burton, A. (1996). Role of autobiographical memory in social problem solving and depression. Journal of Abnormal Psychology, 105, 609-616. doi:10.1037/0021-843X.105.4.609

Grant, B. F., Chou, S. P., Goldstein, R. B., Huang, M. P. H. B., Stinson, F. S., Saha, T. D., ... Ruan, J. R. (2008). Prevalence, correlates, disability, and co-morbidity of DSM-IV borderline personality disorder: Results from the Wave 2 National Epidemiologic Survey on Alcohol and Related Conditions. The Journal of Clinical Psychiatry, 69, 533-545. doi:10.4088/JCP.v69n0404

van Groenestijn, M. A. C., Akkerhuis, G. W., Kupka, R. W., Schneider, N., \& Nolen, W. A. (1999). Gestructureerd Klinisch Interview voor de vaststelling van DSM-IV As I Stoornissen [Structured clinical interview for DSM-IV Axis I disorders]. Amsterdam: Harcourt Test.

Harvey, A. G., Bryant, R., \& Dang, S. T. (1998). Autobiographical memory in acute stress disorder. Journal of Consulting and Clinical Psychology, 66, 500-506. doi:10.1037/0022-066X.66.3.500

Hauer, B. J. A., Wessel, I., Engelhard, I. M., Peeters, L. L., \& Dalgleish, T. (2009). Prepartum autobiographical memory specificity predicts post-traumatic stress symptoms following complicated pregnancy. Memory, 17, 544-556. doi:10.1080/09658210902953836
Hermans, D., Defranc, A., Raes, F., Williams, J. M. G., \& Eelen, P. (2005). Reduced autobiographical memory specificity as an avoidant coping style. British Journal of Clinical Psychology, 44, 583-589. doi:10.1348/014466500163031

Hipwell, A. E., Sapotichne, B., Klostermann, S., Battista, D., \& Keenan, K. (2011). Autobiographical memory as a predictor of depression vulnerability in girls. Journal of Clinical Child \& Adolescent Psychology, 40, 254-265. doi:10.1080/15374416.2011.546037

Horowitz, M., Wilner, M., \& Alvarez, W. (1979). Impact of event scale: A measure of subjective stress. Psychosomatic Medicine, 41, 209218.

Kangas, M., Henry, J. L., \& Bryant, R. A. (2005). A prospective study of autobiographical memory and posttraumatic stress disorder following cancer. Journal of Consulting and Clinical Psychology, 73, 293299. doi:10.1037/0022-006X.73.2.293

Kleim, B., \& Ehlers, A. (2008). Reduced autobiographical memory specificity predicts depression and posttraumatic stress disorder after recent trauma. Journal of Consulting and Clinical Psychology, 76, 231-242. doi:10.1037/0022-006X.76.2.231

Kremers, I. P., Spinhoven, P., \& Van der Does, A. J. W. (2004). Autobiographical memory in depressed and non-depressed patients with borderline personality disorder. British Journal of Clinical Psychology, 43, 17-29. doi:10.1348/014466504772812940

Kremers, I. P., Spinhoven, Ph., Van der Does, A. J. W., \& Van Dyck, R. (2006). Autobiographical memory in depressed and nondepressed patients with borderline personality disorder after long-term psychotherapy. Cognition and Emotion, 20, 448-465. doi:10.1080/ 02699930500342662

Kuyken, W., \& Brewin, C. R. (1995). Autobiographical memory functioning in depression and reports of early abuse. Journal of Abnormal Psychology, 104, 585-591. doi:10.1037/0021-843X.104.4.585

Maffei, C., Fossati, A., Agostini, I., Barraco, A., Bagnato, M., Deborah, D., ... Petrachi, M. (1997). Interrater reliability and internal consistency of the structured clinical interview for DSM-IV Axis II personality disorders (SCID-II). Journal of Personality Disorders, 11, 279-284. doi:10. 1521/pedi.1997.11.3.279

McNally, R. J., Litz, B. T., Prassas, A., Shin, L. M., \& Weathers, F. W. (1994). Emotional priming of autobiographical memory in post-traumatic stress disorder. Cognition and Emotion, 8, 351-367.

Moore, S. A., \& Zoellner, L. A. (2007). Overgeneral autobiographical memory and traumatic events: An evaluative review. Psychological Bulletin, 133, 419-437. doi:10.1037/0033-2909.133.3. 419

Moradi, A. R., Moshirpanahi, S., Parhon, H., Mirzaei, J., Dalgleish, T., \& Jobson, L. A. (2014). A pilot randomized controlled trial investigating the efficacy of memory specificity training in improving symptoms of posttraumatic stress disorder. Behaviour Research and Therapy, 56, 68-74. doi:10.1016/j.brat.2014.03.002

Neshat-Doost, H. T., Dalgleish, T., Yule, W., Kalantari, M., Ahmadi, S. J., Dyregrov, A., \& Jobson, L. (2013). Enhancing autobiographical memory specificity through cognitive training: An intervention for depression translated from basic science. Clinical Psychological Science, 1, 84-92. doi: 10.1177/2167702612454613

Raes, F., Hermans, D., Williams, J. M. G., \& Eelen, P. (2007). A sentence completion procedure as an alternative to the Autobiographical Memory Test for assessing overgeneral memory in non-clinical populations. Memory, 15, 495-507. doi:10.1080/096582107/ 01390982

Raes, F., Williams, J. M. G., \& Hermans, D. (2009). Reducing cognitive vulnerability to depression: A preliminary investigation of memory specificity training (MEST) in inpatients with depressive symptomatology. Journal of Behavior Therapy and Experimental Psychiatry, 40, 24-38. doi:10.1016/j.jbtep.2008.03.001

Renneberg, B., Theobald, E., Nobs, M., \& Weisbrod, M. (2005). Autobiographical memory in borderline personality disorder and depression. Cognitive Therapy and Research, 29, 343-358. doi:10. 1007/s10608-005-4267-4 
Schacter, D. L., Addis, D. R., \& Buckner, R. L. (2007). Remembering the past to imagine the future: The prospective brain. Nature Reviews Neuroscience, 8, 657-661. doi:10.1038/nrm2213

Schotte, C. K., De Doncker, D. A., \& Courjaret, J. (2007). De ADP-IV: Vragenlijst voor DSM-IV As-Il én voor gedragstherapeutische diagnostiek [The ADP-IV: Questionnaire for DSM-IV Axis II and behavioural therapeutic oriented diagnostics]. Gedragstherapie, 40, 111123.

Schotte, C. K., De Doncker, D. A., Dmitruk, D., Van Mulders, I., D'Haenen, H., \& Cosyns, P. (2004). The ADP-IV questionnaire: Differential validity and concordance with the semi-structured interview. Journal of Personality Disorders, 18, 405-419.

Sumner, J. A., Griffith, J. W., \& Mineka, S. (2010). Overgeneral autobiographical memory as a predictor of the course of depression: A meta-analysis. Behaviour Research and Therapy, 48, 614-625. doi:10.1016/j.brat.2010.03.013

Sumner, J. A., Griffith, J. W., Mineka, S., Rekart, K. N., Zinbarg, R. E., \& Craske, M. G. (2011). Overgeneral autobiographical memory and chronic interpersonal stress as predictors of the course of depression in adolescents. Cognition \& Emotion, 25, 183-192. doi:10.1080/02699931003741566

Sumner, J. A., Mineka, S., \& McAdams, D. P. (2013). Specificity in autobiographical memory narratives correlates with performance on the Autobiographical Memory Test and prospectively predicts depressive symptoms. Memory, 21, 646-656. doi:10.1080/ 09658211.2012 .746372

Sutherland, K., \& Bryant, R. A. (2008). Social problem solving and autobiographical memory in posttraumatic stress disorder. Behaviour Research and Therapy, 46, 154-161. doi:10.1016/j.brat.2007.10.005

Van Daele, T., Griffith, J. W., Van den Bergh, O., \& Hermans, D. (2014). Overgeneral autobiographical memory predicts changes in depression in a community sample. Cognition \& Emotion. Advance online publication. doi:10.1080/02699931.2013.879052
Van den Broeck, K. (2015). Specificity and vantage perspective of autobiographical memories in borderline pathology (Unpublished doctoral thesis). KU Leuven, Leuven.

Van den Broeck, K., Claes, L., Pieters, G., Berens, A., \& Raes, F. (in press). Autobiographical memory specificity and non-suicidal self-injury in borderline personality disorder. Journal of Experimental Psychopathology.

Van den Broeck, K., Claes, L., Pieters, G., Hermans, D., \& Raes, F. (2015). Overgeneral memory in borderline personality disorder. In L. A. Watson \& D. Berntsen (Eds.), Clinical perspectives on autobiographical memory (pp. 221-241). Cambridge: Cambridge University Press.

Van der Does, A. J. W. (2002). BDI-II-NL handleiding [BDI-II-Dutch Manal]. Lisse: Psychological, Harcourt Test.

Weertman, A., Arntz, A., \& Kerkhofs, M. L. M. (2000). Gestructureerd diagnostisch interview voor DSM-IV persoonlijkheidsstoornissen (SCID-II) [Structured clinical interview for DSM-IV personality disorders (SCID-II)]. Lisse: Swets Test.

Wessel, I., Merckelbach, H., \& Dekkers, T. (2002). Autobiographical memory specificity, intrusive memory, and general memory skills in Dutch-Indonesian survivors of the World War II era. Journal of Traumatic Stress, 15, 227-234. doi:10.1023/A:1015207428675

Williams, J. M. G., Barnhofer, T., Crane, C., Hermans, D., Raes, F., Watkins, E., \& Dalgleish, T. (2007). Autobiographical memory specificity and emotional disorder. Psychological Bulletin, 133, 122-148. doi:10. 1037/0033-2909.133.1.122

Williams, J. M. G., \& Broadbent, K. (1986). Autobiographical memory in suicide attempters. Journal of Abnormal Psychology, 95, 144-149. doi:10.1037//0021-843X.95.2.144

Zanarini, M. C., Skodol, A. E., Bender, D., Dolan, R., Sanislow, C., Schaefer, E., ... Gunderson, J. G. (2000). The collaborative longitudinal personality disorders study: Reliability of Axis I and Axis II diagnoses. Journal of Personality Disorders, 14, 291-299. doi:10.1521/pedi. 2000.14.4.291 